Delft University of Technology

\title{
Deazaflavins as photocatalysts for the direct reductive regeneration of flavoenzymes
}

van Schie, M. M.C.H.; Younes, S. H.H.; Rauch, M. C.R.; Pesic, M.; Paul, C. E.; Arends, I. W.C.E.; Hollmann, $\mathrm{F}$.

DOI

10.1016/j.mcat.2018.04.015

Publication date

2018

Document Version

Final published version

Published in

Molecular Catalysis

\section{Citation (APA)}

van Schie, M. M. C. H., Younes, S. H. H., Rauch, M. C. R., Pesic, M., Paul, C. E., Arends, I. W. C. E., \& Hollmann, F. (2018). Deazaflavins as photocatalysts for the direct reductive regeneration of flavoenzymes. Molecular Catalysis, 452, 277-283. https://doi.org/10.1016/j.mcat.2018.04.015

\section{Important note}

To cite this publication, please use the final published version (if applicable).

Please check the document version above. 
Green Open Access added to TU Delft Institutional Repository 'You share, we take care!' - Taverne project

\section{https://www.openaccess.nl/en/you-share-we-take-care}

Otherwise as indicated in the copyright section: the publisher is the copyright holder of this work and the author uses the Dutch legislation to make this work public. 


\title{
Deazaflavins as photocatalysts for the direct reductive regeneration of flavoenzymes
}

\author{
M.M.C.H. van Schie ${ }^{a}$, S.H.H. Younes ${ }^{\mathrm{a}, \mathrm{b}}$, M.C.R. Rauch ${ }^{\mathrm{a}}$, M. Pesic ${ }^{\mathrm{a}}$, C.E. Paul ${ }^{\mathrm{c}}$, I.W.C.E. Arends ${ }^{\mathrm{a}}$, \\ F. Hollmann ${ }^{\mathrm{a}, *}$ \\ a Department of Biotechnology, Delft University of Technology, van der Maasweg 9, 2629 HZ, Delft, The Netherlands \\ ${ }^{\mathrm{b}}$ Sohag University, Faculty of Sciences, Department of Chemistry, Sohag 82524, Egypt \\ ${ }^{c}$ Wageningen University \& Research, Laboratory of Organic Chemistry, Stippeneng 4, 6708 WE, Wageningen, The Netherlands
}

\section{A R T I C L E I N F O}

\section{Keywords:}

Flavin

Photochemistry

Biocatalysis

Old yellow enzyme

Oxygen dilemma

\begin{abstract}
A B S T R A C T
Deazaflavins are potentially useful redox mediators for the direct, nicotinamide-independent regeneration of oxidoreductases. Especially the $\mathrm{O}_{2}$-stability of their reduced forms have attracted significant interest for the regeneration of monooxygenases.

In this contribution we further investigate the photochemical properties of deazaflavins and investigate the scope and limitations of deazaflavin-based photoenzymatic reaction systems.
\end{abstract}

\section{Introduction}

Oxidoreductases are amongst the most promising catalysts for preparative organic synthesis for selective reduction, oxidation and oxyfunctionalisation reactions. Amongst them, flavin-dependent oxidoreductases are of particular interest due to the versatility of the flavinprosthetic group for selective reduction [1-5], and oxyfunctionalisation reactions (Scheme 1) [6-9]. For most of these reactions, the catalytic mechanism entails reductive activation of the enzyme-bound flavin cofactor. The reduced flavin cofactor then either reduces a substrate molecule (as in case of the so-called old yellow enzymes or ene reductases) or it reacts with molecular oxygen forming a peroxoflavin capable of selective oxyfunctionalisation reactions such as epoxidation [10-16], Baeyer-Villiger oxidations [17-20], or aromatic hydroxylation reactions [13,21-32].

As mentioned above, all these structurally and mechanistically diverse enzymes have a reductive activation of the enzyme-bound flavin in common. Generally, the reducing equivalents required for this reaction are obtained from the natural nicotinamide cofactors (NAD(P) $\mathrm{H})$. For practical and economic reasons stoichiometric use of $\mathrm{NAD}(\mathrm{P}) \mathrm{H}$ is not feasible, which is why in the past decades a myriad of different in situ regeneration approaches have been developed allowing for the use of NAD(P)H in catalytic amounts only [33-35].

Despite the success of these methodologies, a more direct approach to regenerate the enzyme-bound flavin group could offer some advantages such as simplified reaction schemes. For this, we and others have developed a range of chemical [36-42], electrochemical [43-45], and photochemical [46-51] approaches to target the flavin prosthetic group directly while circumventing the natural nicotinamide cofactor (together with the enzymatic regeneration system).

The mediators of choice for such NAD(P)H-independent regeneration systems are flavins themselves. However, while flavin-based regeneration systems perform well with $\mathrm{O}_{2}$-independent enzymes such as the OYEs, their performance with $\mathrm{O}_{2}$-dependent monooxygenases is rather poor; the major limitation being the poor $\mathrm{O}_{2}$-stability of reduced flavins. One possibility to circumvent this Oxygen Dilemma [52] was suggested by Reetz and coworkers [49], i.e. to utilise deazaflavins instead of the 'normal' ones (Scheme 2) to promote a P450BM3-catalysed aerobic hydroxylation of lauric acid. Compared to using 'normal' flavins, significantly higher productivities were observed, which was attributed to the higher oxidative stability of reduced deazaflavins. These findings are in line with much earlier findings by Massey and coworkers who demonstrated that fully reduced deazaflavins, in contrast to their 'normal' analogues, exhibit a high stability against $\mathrm{O}_{2}$ [53].

Already in the 1970s, deazaflavins have been subject of extensive research efforts. Especially Massey, Hemmerich and coworkers have worked out the reactivity of deazaflavins revealing that the deazasemiquinone radical is significantly less stable compared to the 'normal' semiquinone [53-60]. This favours disproportionation and dimerization reactions leading to non-radical products exhibiting low(er) $\mathrm{O}_{2}$ reactivity. Furthermore, reduction of deazaflavins by exclusive 1 edonors like dithionite proceeds relatively slow compared to natural

\footnotetext{
* Corresponding author.

E-mail address: f.hollmann@tudelft.nl (F. Hollmann).
} 


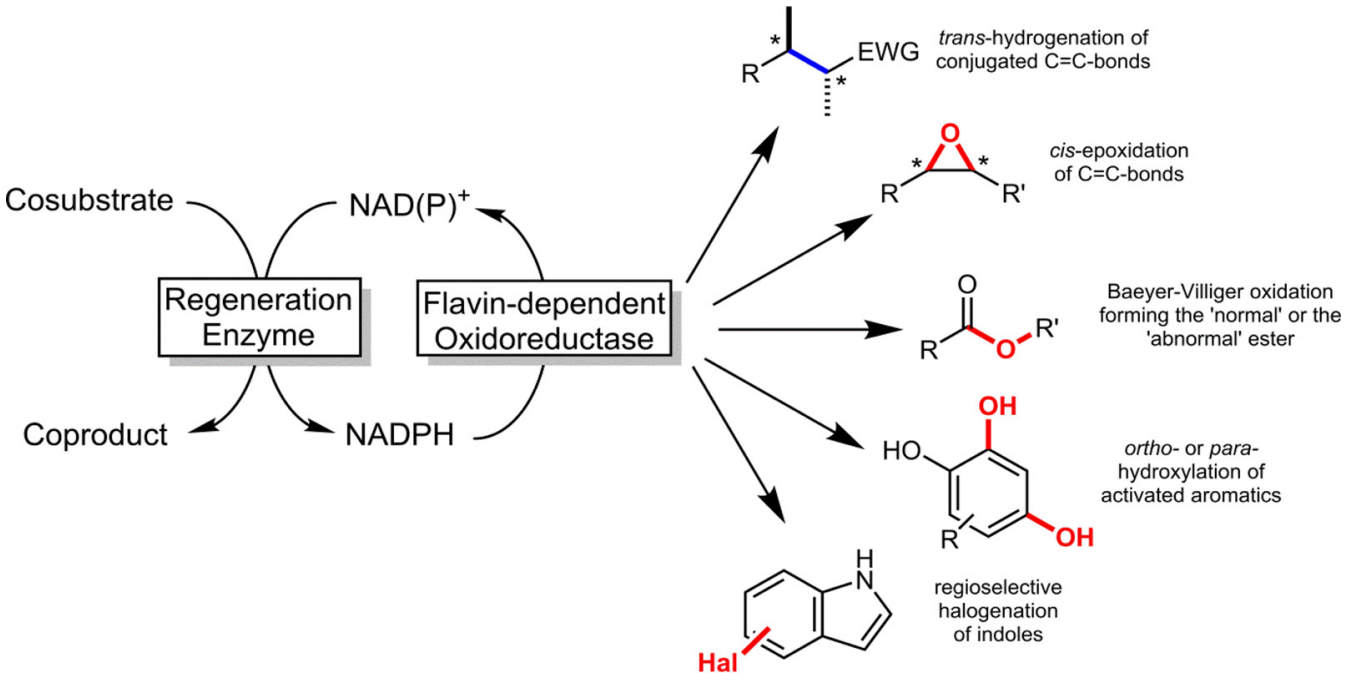

Scheme 1. Simplified scope of flavindependent oxidoreductases for selective reduction of $\mathrm{C}=\mathrm{C}$-double bonds, epoxidations, Baeyer-Villiger oxidations, aromatic hydroxylations and halogenations. All reactions depend on the reduced nicotinamide cofactor, which for economic reasons has to be regenerated in situ using an (enzymatic) regeneration system.<smiles></smiles><smiles>[R]N1C(=O)c2cc3c(C)cc2C=CC1=NC(=O)N3</smiles>

Scheme 2. Simplified representation of flavins (left) and their deazaflavin analogues (right). For reasons of clarity the 5 position wherein both differ are marked.

flavins and via a covalent adduct intermediate.

These findings motivated us to further evaluate the applicability of deazaflavins as photocatalysts/mediators to promote flavoenzyme catalysed reactions.

\section{Materials and methods}

\section{Chemicals}

Chemicals were purchased from Sigma-Aldrich, Fluka, Acros or Alfa-Aesar with the highest purity available and used as received.

5-deazariboflavin (dRf) was synthesized following a literature method (SI for more detailed information) [61]. Stock solutions $(0.2 \mathrm{mM}$ in $100 \mathrm{mM}$ phosphate buffer, $\mathrm{pH} 6)$ of the deazariboflavin were prepared freshly every day.

The old yellow enzyme homologue from Bacillus subtilis (YqjM) was produced and purified using a protocol recently established in our group (SI for more detailed information) [36].

The NADH mimic N-benzyl nicotinamide (BNAH) was synthesized following published procedures $[39,62]$.

\section{Experimental setup}

Photoreduction reactions were performed in $1 \mathrm{ml}$ reaction mixtures in $1.5 \mathrm{ml}$ glass vials. The reaction mixtures were illuminated from all sides from a distance of $10 \mathrm{~cm}$ by a LED light source (SI for more detail). The intensity spectrum of the LED light source was determined by a calibrated spectrophotometer. Samples were gently stirred using Teflon coated magnetic bars. Anaerobic experiments were performed in an anaerobic chamber (on average $98 \% \mathrm{~N}_{2}, 2 \% \mathrm{H}_{2}$ ) with oxygen levels below ppm levels. UV/Vis spectra were recorded using an Avantes DH2000 UV-vis-NIR light source and an Avispec 3648 spectrophotometer.

In a typical experiment $100 \mu \mathrm{M} d R f$ were reduced by $10 \mathrm{mM}$ sacrificial single electron donor or $1 \mathrm{mM}$ hydride donor in a $100 \mathrm{mM} \mathrm{KPi}$ buffer at pH 6.0. The absorbance at $400 \mathrm{~nm}\left(\varepsilon=12500 \mathrm{M}^{-1} \mathrm{~cm}^{-1}\right)$ was followed to determine the oxidation state of dRf over time (Fig. S4.12). Due to interference of absorption when using either hydride donors, the oxidation state was determined by following the absorbance at $430 \mathrm{~nm}$ $\left(\varepsilon=5700 \mathrm{M}^{-1} \mathrm{~cm}^{-1}\right)$.

Due to the FMN, the YqjM has a typical absorbance spectrum with a peak extinction coefficient at $455 \mathrm{~nm}$ which decreases as the FMN in the active site is reduced. At $400 \mathrm{~nm}$ the extinction coefficient does not change significantly with the redox-state of the enzyme, which made it possible to determine the redox-state of the dRf and the YqjM simultaneously. For the reduction of YqjM, a dRf solution was first photoreduced by five equivalents of EDTA. Thereafter, $20 \mu \mathrm{M}$ of YqjM was mixed with $100 \mu \mathrm{M}$ of the reduced dRf.

Photoenzymatic syntheses were performed using $5 \mu \mathrm{M}$ YqjM in the presence of $1 \mathrm{mM}$ of 2-methyl cyclohexenone and $10 \mathrm{mM}$ of EDTA in a $100 \mathrm{mM}$ KPi buffer $\mathrm{pH}$ 6.0. The $2.5 \mathrm{ml}$ reaction mixtures were extracted with $0,5 \mathrm{ml}$ ethyl acetate and analysed on a CP-wax $52 \mathrm{CB}$ GC column $(50 \mathrm{~m} \times 0,53 \mathrm{~m} \times 2 \mu \mathrm{m})\left(\mathrm{GC}\right.$ method: $70{ }^{\circ} \mathrm{C}$ for $2 \mathrm{~min} .2{ }^{\circ} \mathrm{C} / \mathrm{min}-80^{\circ} \mathrm{C}$. $80^{\circ} \mathrm{C}$ for $2 \mathrm{~min} .2{ }^{\circ} \mathrm{C} / \min -90^{\circ} \mathrm{C}$. $90^{\circ} \mathrm{C}$ for $3 \mathrm{~min} .25^{\circ} \mathrm{C} / \min -150^{\circ} \mathrm{C}$. $150{ }^{\circ} \mathrm{C}$ for $1 \mathrm{~min} .25^{\circ} \mathrm{C} / \mathrm{min}-225^{\circ} \mathrm{C} .225^{\circ} \mathrm{C}$ for $1 \mathrm{~min}$ ). $5 \mathrm{mM}$ Dodecane was used as internal standard.

\section{Results and discussion}

5-deazariboflavin (dRf) was synthesized from 3,4-dimethylaniline in

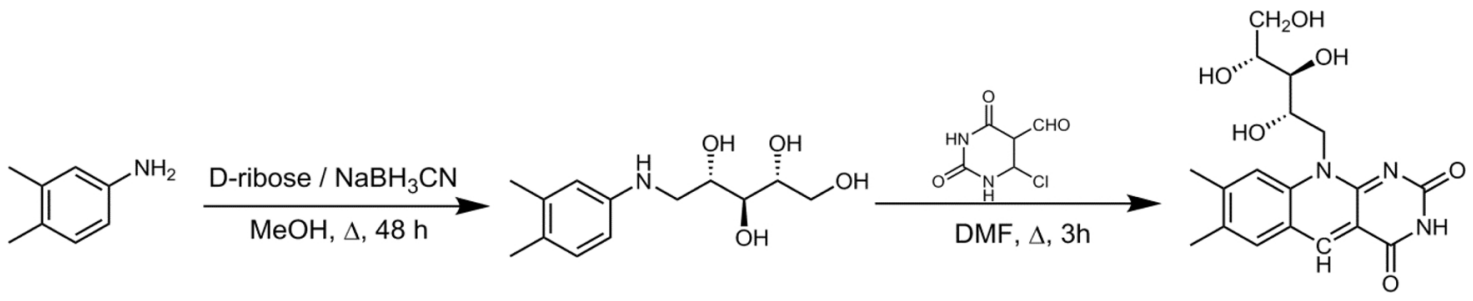

Scheme 3. Synthetic route for 5-deaza riboflavin (dRf). 


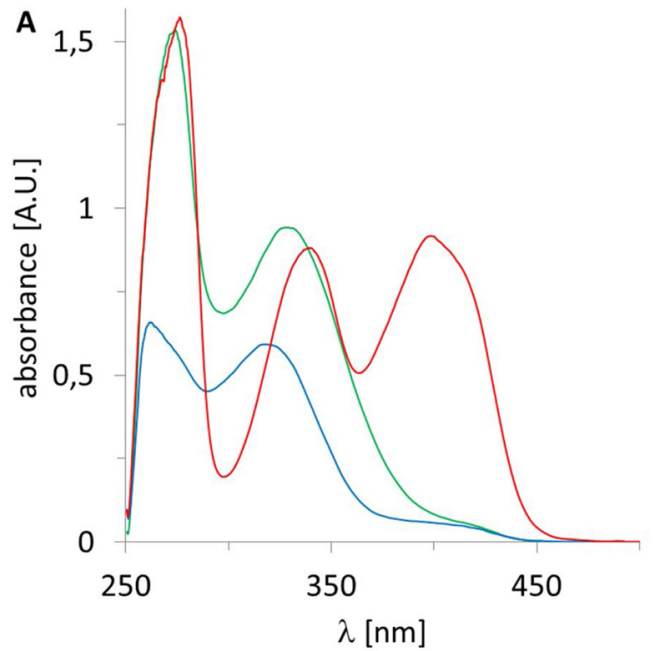

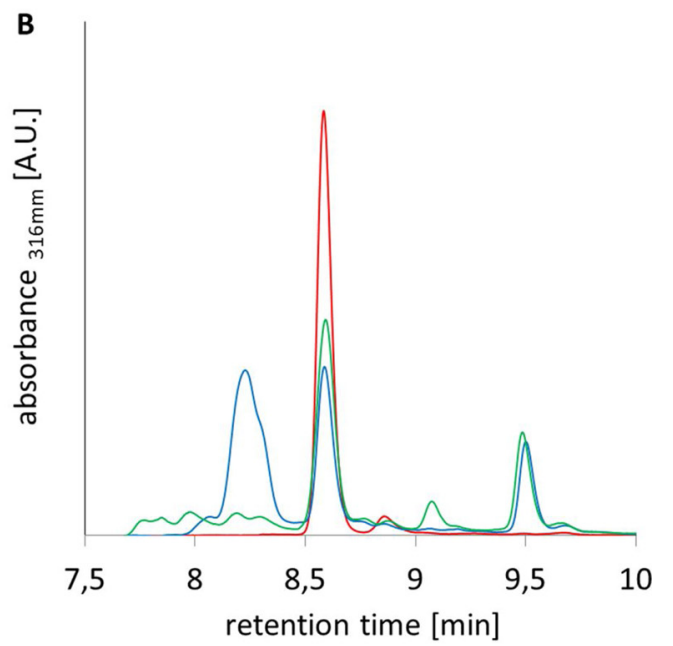

Fig. 1. Photochemical reduction of deazariboflavin (dRf) using NADH or EDTA as sacrificial electron donor. A: $\mathrm{UV} / \mathrm{Vis}$ spectra of the various dRf species observed during the photoreduction of $\mathrm{dRf}^{\text {ox }}$ (red) with EDTA (blue) and NADH (green). General conditions: $75 \mu \mathrm{M}$ of dRf, $10 \mathrm{mM}$ EDTA or $75 \mu \mathrm{M}$ NADH, $100 \mathrm{mM}$ KPi buffer pH 6.0, Blue LED light setup, max light intensity, anaerobic conditions, RT. B: HPLC chromatograms recorded of photochemical reductions of dRf (red) using NADH (green) or EDTA (blue) as stoichiometric reductant. (For interpretation of the references to colour in this figure legend, the reader is referred to the web version of this article.)

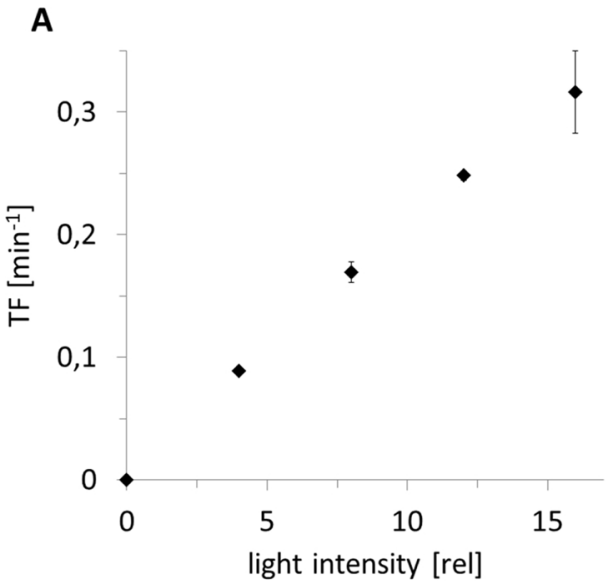

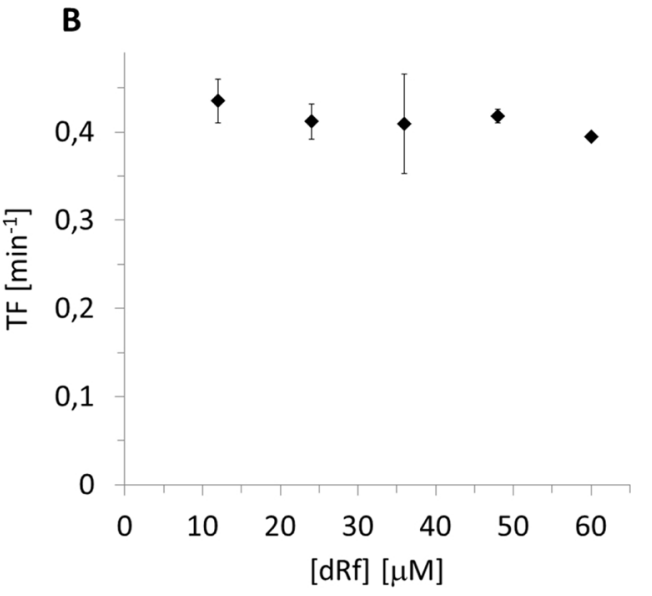

B

D

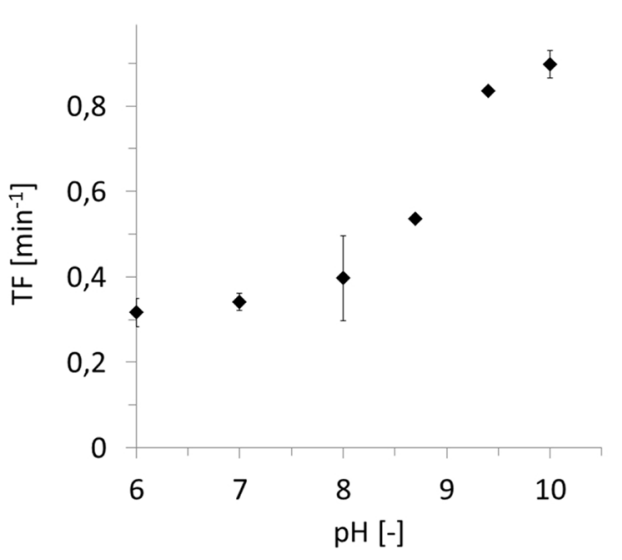

Fig. 2. Dependency of the $\mathrm{dRf}$ reduction rate (expressed as turnover frequency of dRf, TF) on A: intensity of the blue LED light source, B: $\mathrm{dRf}^{\mathrm{ox}}$ concentration, C: Concentration of the sacrificial electron donor and D: $\mathrm{pH}$. General conditions: $60 \mu \mathrm{M}$ of $\mathrm{dRf}^{\text {ox }}, 10 \mathrm{mM}$ EDTA, $100 \mathrm{mM} \mathrm{KPi}$ buffer $\mathrm{pH}$ 6.0, blue LED light setup, max light intensity, anaerobic conditions, $\mathrm{RT}$. TF $=$ (initial $\mathrm{dRf}$ reduction rate $[\mu \mathrm{M}$ $\left.\left.\min ^{-1}\right]\right) \times(\mathrm{c}(\mathrm{dRf})[\mu \mathrm{M}])^{-1}$.
C

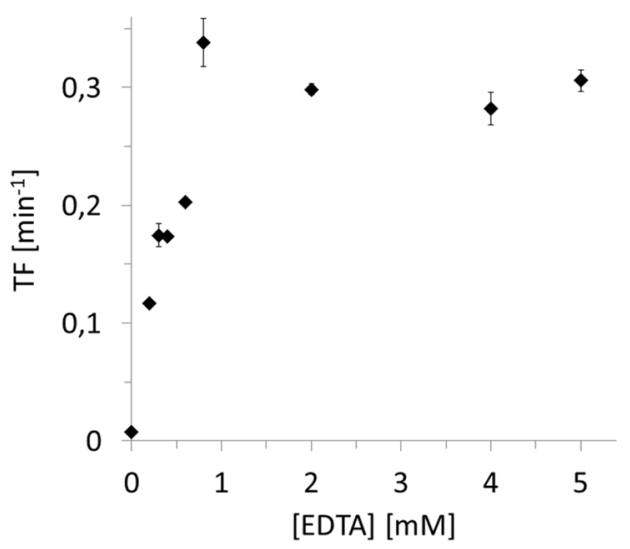

being BNAH, with which also in the dark, significant formation of $\mathrm{H}_{2} \mathrm{dRf}$ was observed. One possible explanation for this may be the more negative redox potential of BNAH compared to $\mathrm{NADH}(-0.36 \mathrm{~V}$ and $-0.315 \mathrm{~V}$ SHE, respectively) [63].

The spectra of single electron donor- and hydride-donor reduced dRfs differed significantly in shape suggesting different reduction products. This assumption was corroborated by chromatographic separation of the reaction products (Fig. 1B). While NADH-reduced dRf gave only one product $\left(\mathrm{H}_{2} \mathrm{dRf}\right.$, as confirmed by its characteristic UV spectrum, Fig. S4.1) [56] EDTA-reduction of dRf yielded $\mathrm{H}_{2} \mathrm{dRf}$ and another product (most likely assigned to the dimeric, half-reduced semiquinone 

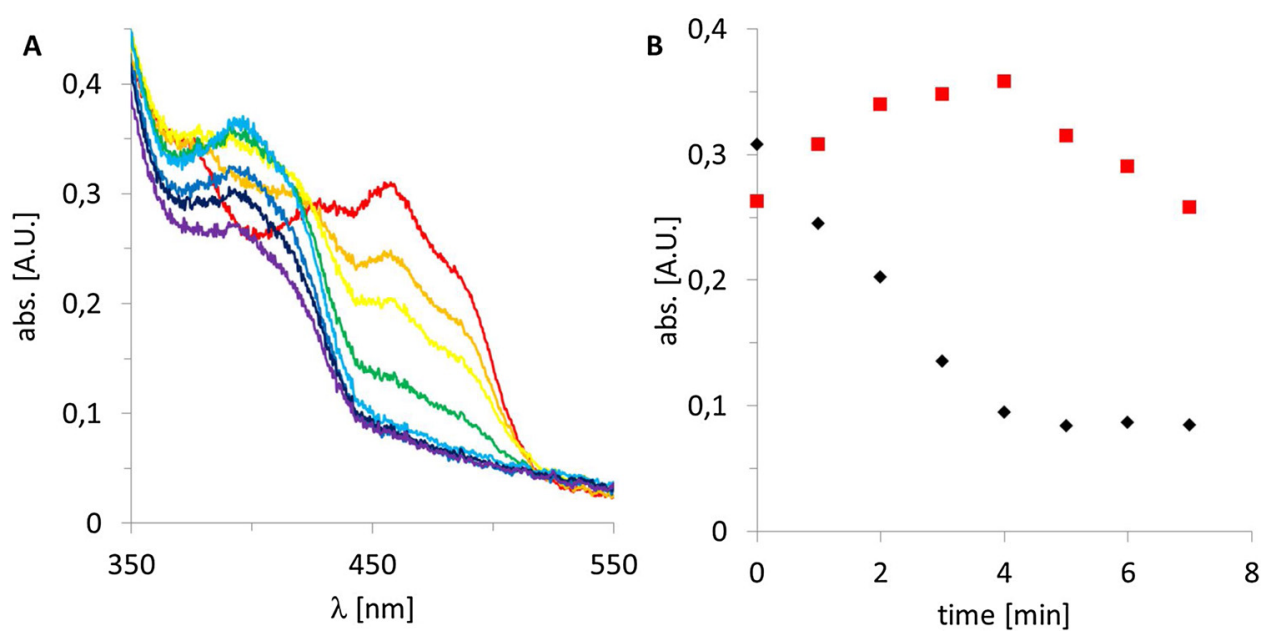

Fig. 3. Time course of the $(\mathrm{dRf})_{2}{ }^{\text {red }}$ mediated reduction of YqjM. A: spectra recorded over time (1 min intervals) and B: time courses of the characteristic absorption maxima for YajM$\mathrm{FMN}^{\mathrm{ox}}(290 \mathrm{~nm}, \diamond)$ and $\mathrm{dRf}^{\text {ox }}(355 \mathrm{~nm}, \square)$. Conditions: A solution of $60 \mu \mathrm{M} \mathrm{dRf}^{\text {ox }}$ in $100 \mathrm{mM}$ KPi buffer containing $0.5 \mathrm{mM}$ EDTA was illuminated (blue LED) until full reduction was achieved, afterwards, this reaction mixture was supplemented with the same volume of $40 \mu \mathrm{M}$ YqjM (in the same buffer) and subsequently illuminated using a blue LED [71]. (For interpretation of the references to colour in this figure legend, the reader is referred to the web version of this article.)
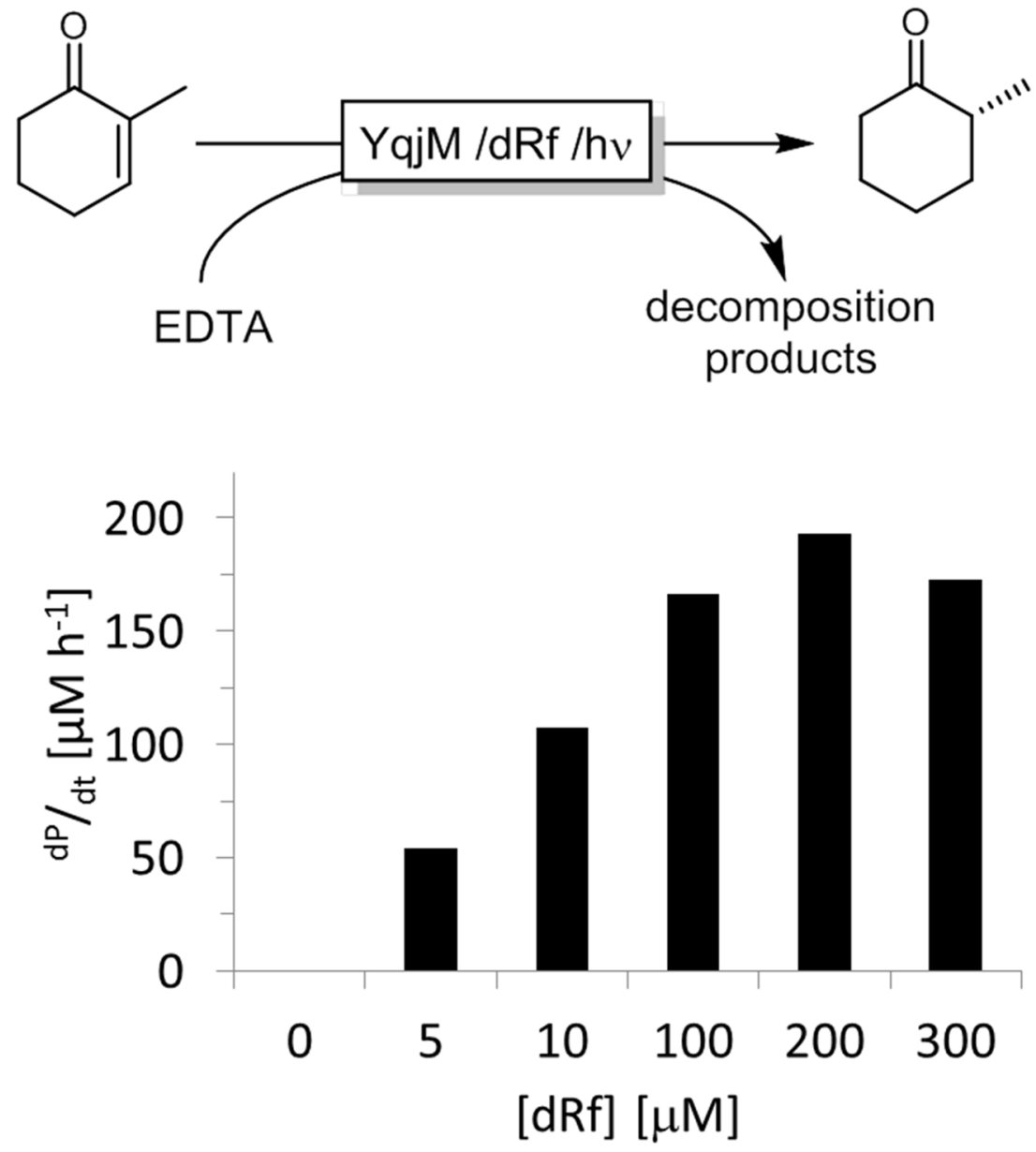

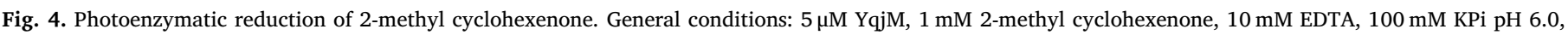

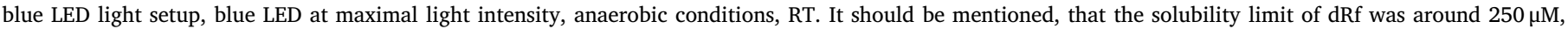
therefore, the sample at $300 \mu \mathrm{M} d \mathrm{dR}$ was turbid, which possibly influenced the regeneration reaction.

product) appearing simultaneously over time (Fig. S4.2). These findings are in line with previous reports using EDTA or $\mathrm{NaBH}_{4}$ as reductants $[58,64]$.

Next, we characterised the light-driven reduction of $\mathrm{dRf}^{\mathrm{ox}}$ using EDTA as a sacrificial electron donor in some more detail. It is worth mentioning here that the photochemical reduction of $\mathrm{dRf}$ proceeded approximately 14 times slower than the reduction of 'normal' riboflavin. This is most likely attributed to the better overlap of the riboflavin absorption spectrum with the emission spectrum of the LED used in this study (Fig. S4.5) [65]. However, also differences in the redox potentials of Rf ( $-0.146 \mathrm{~V}$ vs. SHE) and dRf $(-0.237 \mathrm{~V}$ vs. SHE) may contribute [66]. Using the Nernst equation, the redox potential of dRf was estimated to be $-0.332 \mathrm{~V}$ vs. SHE at $\mathrm{pH} 6.0$ (see SI for the calculations).

The reduction rate of $\mathrm{dRf}$ was linearly dependent on the light intensity applied (Figs. 2 A, S4.6). Likewise the overall rate of dRf reduction linearly depended on the dRf concentration itself (Fig. 2B). Hence, we conclude that the in situ concentration of photoexcited dRf is 


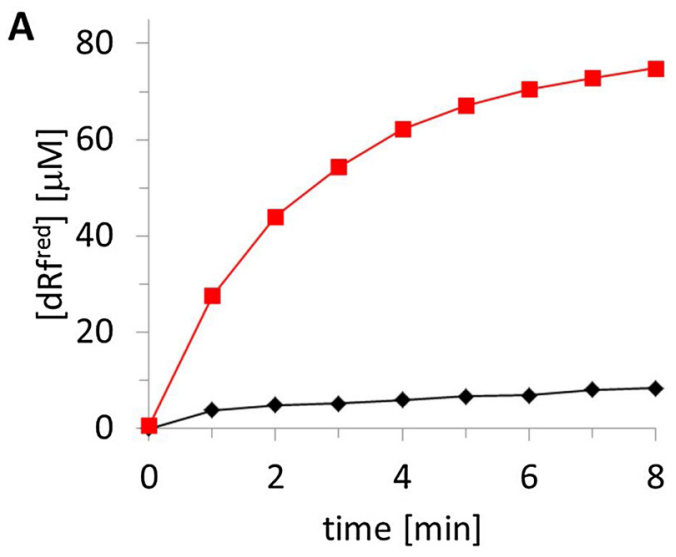

Table 1

Aerobic reoxidation rates observed for deazariboflavin reduced by EDTA or $\mathrm{NADH}$.

\begin{tabular}{lll}
\hline & \multicolumn{2}{l}{ Reoxidation rate $\left[\mu \mathrm{M} \mathrm{h}^{-1}\right]$} \\
\cline { 2 - 3 } & Dark & Light \\
\hline$(\mathrm{dRf})_{2}$ & 1.7 & 96 \\
$\mathrm{H}_{2} \mathrm{dRf}$ & 0.78 & 30 \\
\hline
\end{tabular}

Conditions: $10 \mathrm{mM}$ EDTA or $1 \mathrm{mM}$ NADH, $100 \mathrm{mM}$ KPi buffer pH 6.0, blue LED light setup, max light intensity, RT.

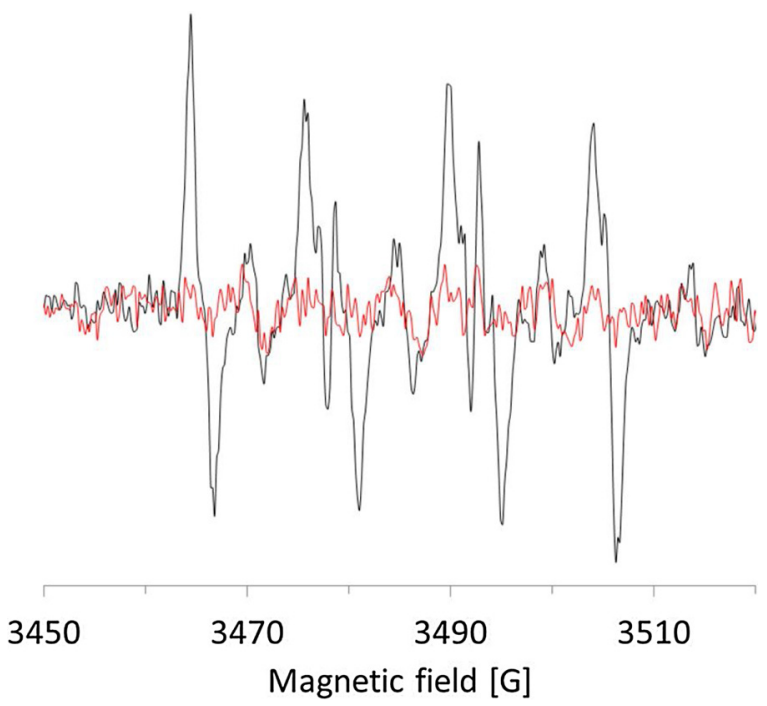

Fig. 6. EPR spectra recorded using the spin trap technique during the aerobic reduction of dRf with BNAH under illumination (black) and in dark (red). Conditions: $60 \mu \mathrm{M}$ dRf, $1 \mathrm{mM}$ BNAH, 1\% v/v DMSO, $100 \mathrm{mM} \mathrm{KPi} \mathrm{pH} \mathrm{6.0,} \mathrm{Kaiser}$ Fibre Optic Lighting system $15 \mathrm{~V}, 150 \mathrm{~W}$, on half intensity, aerobic conditions. (For interpretation of the references to colour in this figure legend, the reader is referred to the web version of this article.)

overall rate limiting. Varying the concentration of the sacrificial electron donor (EDTA) revealed a saturation-type dependency of the dRf reduction rate on the EDTA concentration applied (Fig. 2C). Above approximately 1.5-2 mM EDTA ( $\mathrm{pH} \mathrm{6}$ ), no further increase of the dRf reduction rate was observed. Finally, there was a sigmoidal $\mathrm{pH}$-dependency of the $\mathrm{dRf}^{\text {ox }}$ reduction rate with a turning point at approximately $\mathrm{pH} 9$ (Fig. 2D). Interestingly, using MOPS instead of EDTA shifted this turning point to $\mathrm{pH} 7$ (Fig. S4.7). Furthermore, the substitution pattern of the $\mathrm{N}$-atom in the sacrificial electron donor had an influence on the reduction rate (Fig. S4.4). Overall, it appears that
Fig. 5. Photochemical reduction of deazariboflavin using NADH (A) or EDTA (B) as sacrificial electron donor under aerobic $(\diamond)$ and anaerobic $(\square)$ conditions. Conditions: $10 \mathrm{mM}$ EDTA or $1 \mathrm{mM} \mathrm{NADH}, 100 \mathrm{mM}$ KPi buffer $\mathrm{pH}$ 6.0, blue LED light setup, max light intensity, RT. (For interpretation of the references to colour in this figure legend, the reader is referred to the web version of this article.) higher electron densities around the $\mathrm{N}$-atom of the donors facilitate the electron transfer to dRf. These observations are in line with the oxidation mechanism suggested by Kramer and coworkers [67]. These authors suggested a methylene radical intermediate being formed after single electron transfer of the amino acid donor and subsequent decarboxylation. The extend of hyperconjugative stabilisation of this intermediate radical should increase with the N-substitution pattern as well as with occurrence of a non-protonated N-substituent.

To further examine the applicability of photoreduced $\mathrm{dRf}^{\text {red }}$ to regenerate oxidoreductases, we used it to reduce the FMN-dependent old yellow enzyme homologue from Bacillus subtilis (YqjM) $[36,68,69]$. The different spectral properties of $\mathrm{dRf}^{\mathrm{ox}}\left(\lambda_{\max }=390 \mathrm{~nm}\right)$ and YqjM-bound $\mathrm{FMN}^{\mathrm{ox}}\left(\lambda_{\max }=455 \mathrm{~nm}\right)$ allow for the simultaneous determination and quantification of the electron transfer between photoregenerated $\mathrm{dRf}^{\text {red }}$ and YqjM-bound $\mathrm{FMN}^{\mathrm{ox}}$ (Fig. 3). In accordance to previous findings by Massey and Hemmerich [70] we found that photoregeneration of YqjM was possible. Using e.g. 1.5 eq of (prior reduced) dRf full reduction of YqjM was observed within 4 minutes. This reaction was observed under blue light illumination only. Incubation of YqjM with prereduced dRf in the dark or upon illumination with other wavelengths yielded no significant reduction of the YqjM-bound FMN (Fig. S4.8). Currently, we are lacking a satisfactory explanation for this observation. Possibly the interaction of $(\mathrm{dRf})_{2}{ }^{\text {red }}$ with the enzyme-bound FMN is sterically hindered and photoexcitation of the latter may accelerated the long-distance electron transfer.

To test if catalytic turnover of both, $\mathrm{dRf}$ and YqjM is feasible, we used the enantioselective reduction of 2-methyl cyclohexanone to $(R)$ 2-methyl cyclohexanone as model reaction (Fig. 4). In the absence of $\mathrm{dRf}$ no conversion of the starting material was observed indicating that direct photochemical reduction of YqjM-bound FMN by EDTA was not efficient. However, already in the presence of $5 \mu \mathrm{M}$ dRf (equimolar to YqjM) a product formation rate of approximately $50 \mu \mathrm{Mh}^{-1}$ was observed. Hence, a turnover frequency of approximately $10 \mathrm{~h}^{-1}$ was calculated for YqjM and dRf. This corresponds well to the YqjM-reduction rate observed before (Fig. 3) indicating that the reduction of the biocatalyst was overall rate-limiting. The overall rate of the photoenzymatic reduction reaction increased steadily with increasing photocatalyst concentration (up to $200 \mu \mathrm{M}$, representing the solubility limit for dRf). With it, the catalytic efficiency of YqjM increased to $40 \mathrm{~h}^{-1}$. It is worth mentioning that in all experiments $(R)$-2-methyl cyclohexanone was formed almost exclusively (Fig. S4.9).

While these numbers are comparable to recently reported photoenzymatic systems, [46] the catalytic performance of YqjM falls back by orders of magnitude behind its potential $\left(1.8 \mathrm{~s}^{-1}\right.$ using NADPH as reductant) [36]. A plausible explanation for this is to assume an unfavourable interaction of the reduced dRf mediators with the enzymebound FMN resulting in poor electron transfer rates. Both, cofactor- and enzyme engineering may generate artificial binding sites and thereby accelerate the regeneration reaction $[72,73]$. 
Finally, we re-visited the $\mathrm{O}_{2}$-stability of reduced dRfs. As mentioned above, significant reduction of YqjM-bound FMN and product formation in the photoenzymatic system was observed only under strictly anaerobic conditions. We therefore investigated the influence of $\mathrm{O}_{2}$ on the photochemical reduction of dRf (Fig. 5). Independent from the sacrificial electron donor used (NADH or EDTA) reduction of dRf was observed under anaerobic conditions only while it was negligible in the presence of $\mathrm{O}_{2}$. In the latter cases, $\mathrm{H}_{2} \mathrm{O}_{2}$ was detectable as well as $\mathrm{NADH}$ oxidation (in case of Fig. $5 \mathrm{~A}$ ) suggesting $\mathrm{dRf}^{\text {red }}$ reoxidation occurring simultaneously.

Therefore, we determined the reoxidation rates of photochemically reduced dRf in the dark and under illumination (Table 1). Both, the dimeric ( $\mathrm{dRf})_{2}$ as well as the fully reduced $\mathrm{H}_{2} \mathrm{dRf}$ were rather stable against $\mathrm{O}_{2}$ in the dark whereas they swiftly reoxidized in the presence of (blue) light. Similar observations had previously been made by Hemmerich and coworkers [58].

The influence of light can be rationalised assuming that (trace amounts) of photoexcited, oxidised dRf synproportionate with $\mathrm{H}_{2} \mathrm{dRf}$ or $(\mathrm{dRf})_{2}$ forming a reactive semiquinone radical reacting with $\mathrm{O}_{2}$ via single electron transfer. This reaction should be autocatalytic, for which we have found indications in the reoxidation time-course (Figure $S$ 4.10). Furthermore, EPR-measurements during BNAH-mediated reduction of dRf in the presence and absence of light support this assumption (Figs. 6 and S4.12). As dRf also is a photosensitiser capable of generating singlet oxygen $\left({ }^{1} \mathrm{O}_{2}\right)$ [74], an involvement of ${ }^{1} \mathrm{O}_{2}$ cannot be ruled out completely. ${ }^{1} \mathrm{O}_{2}$-oxidations, however, generally do not involve radical species, which is in contrast to the observations of radicals mentioned above.

\section{Conclusions}

Direct reductive regeneration of flavoenzymes circumventing the expensive and unstable nicotinamide cofactors is an attractive alternative to established systems utilizing the nicotinamide cofactor together with an (enzymatic) regeneration system.

In case of $\mathrm{O}_{2}$-dependent enzymes, the Oxygen Dilemma, however, severely impairs the utility of these approaches. While the high reactivity of 'normal flavins' with molecular oxygen is well-known [75], reduced deazaflavins are considered to be much more stable due to the spin-forbidden character of the reoxidation with triplett oxygen $\left({ }^{3} \mathrm{O}_{2}\right)$ [52]. This motivated us to evaluate 5-deazariboflavin (dRf) as photocatalyst and mediator to regenerate flavin-dependent enzymes. Indeed, fully reduced $\mathrm{H}_{2} \mathrm{dRf}$ is fairly stable in the presence of molecular oxygen. In the presence of oxidised $\mathrm{dRf}$ (especially if illuminated), however, radical species are formed via synproportionation, which react quickly with molecular oxygen (Scheme 4) [58].

Indeed, neither accumulation of reduced $\mathrm{dRf}$ or catalytic turnover was observed under aerobic conditions. Therefore, we conclude that a simple one-pot reaction cascade entailing photochemical reduction of $\mathrm{dRf}$ and biocatalytic reaction is not feasible due to the uncoupling reaction described above.

Possibly, technical solutions such as compartmentalised reaction

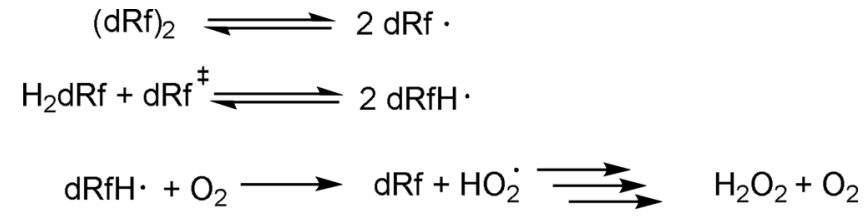

Scheme 4. Aerobic reoxidation of reduced deazaflavin species. The reactive semiquinone radical (dRf) reacts fast with $\mathrm{O}_{2}$ eventually leading to $\mathrm{H}_{2} \mathrm{O}_{2}$ and $\mathrm{O}_{2}$. dRf itself is formed either via the dimerization equilibrium of $(\mathrm{dRf})_{2}$ or through synproportionation of $\mathrm{H}_{2} \mathrm{dRf}$ with (photoexcited) dRf. For reasons of simplicity, protonation equilibria have not been included in this scheme. setups (anaerobic reduction of the flavin followed by aerobic biocatalytic reaction) as suggested by Schmid and coworkers [43] may be doable.

\section{Conflict of interest}

None.

\section{Acknowledgements}

We thank the Netherlands Organisation for Scientific Research for financial support through a VICI grant (No. 724.014.003). Excellent technical support by M. Gorseling and support by Prof. W.R. Hagen with the EPR measurements is gratefully acknowledged.

\section{Appendix A. Supplementary data}

Supplementary data associated with this article can be found, in the online version, at http://dx.doi.org/10.1016/j.mcat.2018.04.015.

\section{References}

[1] H.S. Toogood, N.S. Scrutton, New developments in 'ene'-reductase catalysed biological hydrogenations, Curr. Opin. Chem. Biol. 19 (0) (2014) 107-115.

[2] H.S. Toogood, J.M. Gardiner, N.S. Scrutton, Biocatalytic reductions and chemical versatility of the old yellow enzyme family of flavoprotein oxidoreductases, ChemCatChem 2 (8) (2010) 892-914.

[3] B.M. Nestl, S.C. Hammer, B.A. Nebel, B. Hauer, New generation of biocatalysts for organic synthesis, Angew. Chem. Int. Ed. 53 (2014) 3070-3095.

[4] R. Stürmer, B. Hauer, M. Hall, K. Faber, Asymmetric bioreduction of activated CC bonds using enoate reductases from the old yellow enzyme family, Curr. Opin. Chem. Biol. 11 (2) (2007) 203-213.

[5] F. Hollmann, I.W.C.E. Arends, D. Holtmann, Enzymatic reductions for the chemist, Green Chem. 13 (9) (2011) 2285-2313.

[6] R.T. Winter, M.W. Fraaije, Applications of flavoprotein oxidases in organic synthesis: novel reactivities that go beyond amine and alcohol oxidations, Curr. Org. Chem. 16 (21) (2012) 2542-2550.

[7] G. de Gonzalo, M.W. Fraaije, Recent developments in flavin-based catalysis, ChemCatChem 5 (2) (2012) 403-415.

[8] F. Hollmann, I.W.C.E. Arends, K. Buehler, A. Schallmey, B. Bühler, Enzyme-mediated oxidations for the chemist, Green Chem. 13 (2011) 226-265.

[9] M.M.E. Huijbers, S. Montersino, A.H. Westphal, D. Tischler, W.J.H. van Berkel, Flavin dependent monooxygenases, Arch. Biochem. Biophys. 544 (2014) 2-17.

[10] A. Schmid, K. Hofstetter, H.-J. Feiten, F. Hollmann, B. Witholt, Integrated biocatalytic synthesis on gram scale: the highly enantioselective preparation of chiral oxiranes with styrene monooxygenase, Adv. Synth. Catal. 343 (6-7) (2001) 732-737.

[11] S. Panke, M.G. Wubbolts, A. Schmid, B. Witholt, Production of enantiopure styrene oxide by recombinant Escherichia coli synthesizing a two-component styrene monooxygenase, Biotechnol. Bioeng. 69 (1) (2000) 91-100.

[12] S. Panke, B. Witholt, A. Schmid, M.G. Wubbolts, Towards a biocatalyst for (S)styrene oxide production: characterization of the styrene degradation pathway of Pseudomonas sp. strain VLB120, Appl. Environ. Microbiol. 64 (6) (1998) 2032-2043.

[13] S. Montersino, D. Tischler, G.T. Gassner, W.J.H.V. Berkel, Berkel, catalytic and structural features of flavoprotein hydroxylases and epoxidases, Adv. Synth. Catal. 353 (13) (2011) 2301-2319.

[14] D. Tischler, D. Eulberg, S. Lakner, S.R. Kaschabek, W.J.H. van Berkel, M. Schlomann, Identification of a novel self-sufficient styrene monooxygenase from rhodococcus opacus 1CP, J. Bacteriol. 191 (15) (2009) 4996-5009.

[15] H. Toda, T. Ohuchi, R. Imae, N. Itoh, Microbial production of aliphatic (S)-epoxyalkanes by using rhodococcus sp strain ST-10 styrene monooxygenase expressed in organic-Solvent-Tolerant kocuria rhizophila DC2201, Appl. Environ. Microbiol. 81 (6) (2015) 1919-1925.

[16] H. Toda, R. Imae, N. Itoh, Bioproduction of chiral epoxyalkanes using styrene monooxygenase from rhodococcus sp ST-10 (RhSMO), Adv. Synth. Catal. 356 (16) (2014) 3443-3450.

[17] N. Oberleitner, A.K. Ressmann, K. Bica, P. Gartner, M.W. Fraaije, U.T. Bornscheuer, F. Rudroff, M.D. Mihovilovic, From waste to value - direct utilization of limonene from orange peel in a biocatalytic cascade reaction towards chiral carvolactone, Green Chem. 19 (2) (2017) 367-371.

[18] M.J. Fink, F. Rudroff, M.D. Mihovilovic, Baeyer-Villiger monooxygenases in aroma compound synthesis, Bioorg. Med. Chem. 21 (20) (2011) 6135-6138.

[19] J. Rehdorf, M.D. Mihovilovic, M.W. Fraaije, U.T. Bornscheuer, Enzymatic synthesis of enantiomerically pure beta-amino ketones beta-Amino esters, and beta-Amino alcohols with baeyer-villiger monooxygenases, Chem. Eur. J. 16 (31) (2010) 9525-9535.

[20] J. Rehdorf, M.D. Mihovilovic, U.T. Bornscheuer, Exploiting the Regioselectivity of Baeyer-Villiger Monooxygenases for the Formation of beta-Amino Acids and beta- 
Amino Alcohols, Angew. Chem. Int. Ed. 49 (26) (2010) 4506-4508.

[21] J. Lutz, F. Hollmann, T.V. Ho, A. Schnyder, R.H. Fish, A. Schmid, Bioorganometallic chemistry: biocatalytic oxidation reactions with biomimetic NAD + /NADH co-factors and $[\mathrm{Cp} * \mathrm{Rh}(\mathrm{bpy}) \mathrm{H}]+$ for selective organic synthesis, J. Organomet. Chem. 689 (25) (2004) 4783-4790.

[22] A. Meyer, A. Schmid, M. Held, A.H. Westphal, M. Rothlisberger, H.P.E. Kohler, W.J.H. van Berkel, B. Witholt, Changing the substrate reactivity of 2-hydroxybiphenyl 3-monooxygenase from Pseudomonas azelaica HBP1 by directed evolution, J. Biol. Chem. 277 (7) (2002) 5575-5582.

[23] J. Lutz, V.V. Mozhaev, Y.L. Khmelnitsky, B. Witholt, A. Schmid, Preparative application of 2-hydroxybiphenyl 3-monooxygenase with enzymatic cofactor regeneration in organic-aqueous reaction media, J. Mol. Catal. B. Enzym. 19-20 (2002) 177-187.

[24] F. Hollmann, A. Schmid, E. Steckhan, The first synthetic application of a monooxygenase employing indirect electrochemical NADH regeneration, Angew. Chem. Int. Ed. 40 (1) (2001) 169-171.

[25] M. Held, A. Schmid, H.P.E. Kohler, W. Suske, B. Witholt, M.G. Wubbolts, An integrated process for the production of toxic catechols from toxic phenols based on a designer biocatalyst, Biotechnol. Bioeng. 62 (6) (1999) 641-648.

[26] M. Held, W. Suske, A. Schmid, K.H. Engesser, H.P.E. Kohler, B. Witholt, M.G. Wubbolts, Preparative scale production of 3-substituted catechols using a novel monooxygenase from Pseudomonas azelaica HBP 1, J. Mol. Catal. B. Enzym. 5 (1-4) (1998) 87-93.

[27] W.A. Suske, M. Held, A. Schmid, T. Fleischmann, M.G. Wubbolts, H.-P.E. Kohler, Purification and Characterization of 2-Hydroxybiphenyl 3-Monooxygenase, a Novel NADH-dependent, FAD-containing Aromatic Hydroxylase from Pseudomonas azelaica HBP1, J. Biol. Chem. 272 (39) (1997) 24257-24265.

[28] G. Gygli, W.J.H. van Berkel, Oxizymes for biotechnology, Curr. Biotechnol. 4 (2) (2015) 100-110.

[29] J. Sucharitakul, C. Tongsook, D. Pakotiprapha, W.J.H. van Berkel, P. Chaiyen, The reaction dinetics of 3-Hydroxybenzoate 6-Hydroxylase from Rhodococcus jostii RHA1 provide an understanding of the para-Hydroxylation enzyme catalytic cycle, J. Biol. Chem. 288 (49) (2013) 35210-35221.

[30] S. Montersino, R. Orru, A. Barendregt, A.H. Westphal, E. van Duijn, A. Mattevi, W.J.H. van Berkel, Crystal structure of 3-Hydroxybenzoate 6-Hydroxylase uncovers lipid-assisted flavoprotein strategy for regioselective aromatic hydroxylation, J. Biol. Chem. 288 (36) (2013) 26235-26245.

[31] S. Kara, D. Spickermann, J.H. Schrittwieser, C. Leggewie, W.J.H. Van Berkel, I.W.C.E. Arends, F. Hollmann, More efficient redox biocatalysis by utilising 1,4butanediol as 'smart cosubstrate', Green Chem. 15 (2013) 330-335.

[32] S. Montersino, W.J.H. van Berkel, Functional annotation and characterization of 3hydroxybenzoate 6-hydroxylase from Rhodococcus jostii RHAl, BBA-Proteins Proteomics 1824 (3) (2012) 433-442.

[33] S. Kara, J.H. Schrittwieser, F. Hollmann, M.B. Ansorge-Schumacher, Recent trends and novel concepts in cofactor-dependent biotransformations, Appl. Microbiol. Biotechnol. 98 (4) (2014) 1517-1529.

[34] R. Wichmann, D. Vasic-Racki, Cofactor Regeneration at the Lab Scale, Technology Transfer in Biotechnology: From Lab to Industry to Production, Springer-Verlag Berlin, Berlin, 2005, pp. 225-260.

[35] H. Chenault, G. Whitesides, Regeneration of nicotinamide cofactors for use in organic synthesis, App. Biochem. Biotechnol. 14 (2) (1987) 147-197.

[36] M. Pesic, E. Fernández-Fueyo, F. Hollmann, Characterization of the old yellow enzyme homolog from bacillus subtilis (YqjM), ChemistrySelect 2 (13) (2017) 3866-3871.

[37] C.E. Paul, D. Tischler, A. Riedel, T. Heine, N. Itoh, F. Hollmann, Non-enzymatic regeneration of styrene monooxygenase for catalysis, ACS Catal. 5 (2015) 2961-2965.

[38] C.E. Paul, I.W.C.E. Arends, F. Hollmann, Is simpler better? Synthetic nicotinamide cofactor analogues for redox chemistry, ACS Catal. 4 (2014) 788-797.

[39] C.E. Paul, S. Gargiulo, D.J. Opperman, I. Lavandera, V. Gotor-Fernandez, V. Gotor, A. Taglieber, Arends I.W.C.E, F. Hollmann, Mimicking nature synthetic nicotinamide cofactors for CC bioreduction using enoate reductases, Org. Lett. 15 (1) (2013) 180-183.

[40] S. Unversucht, F. Hollmann, A. Schmid, K.-H. van Pée, $\mathrm{FADH}_{2}$-dependence of tryptophan 7-halogenase, Adv. Synth. Catal. 347 (7-8) (2005) 1163-1167.

[41] F. Hollmann, P.C. Lin, B. Witholt, A. Schmid, Stereospecific biocatalytic epoxidation: the first example of direct regeneration of a FAD-dependent monooxygenase for catalysis, J. Am. Chem. Soc. 125 (27) (2003) 8209-8217.

[42] C.K. Winkler, D. Clay, M. Entner, M. Plank, K. Faber, NAD(P)H-Independent asymmetric CC bond reduction catalyzed by ene reductases by using artificial Cosubstrates as the hydrogen donor, Chem. - Eur. J. 20 (5) (2014) 1403-1409.

[43] R. Ruinatscha, C. Dusny, K. Buehler, A. Schmid, Productive asymmetric styrene epoxidation based on a next generation electroenzymatic methodology, Adv. Synth. Catal. 351 (14-15) (2009) 2505-2515.

[44] R. Ruinatscha, V. Hollrigl, K. Otto, A. Schmid, Productivity of selective electroenzymatic reduction and oxidation reactions: theoretical and practical considerations, Adv. Synth. Catal. 348 (15) (2006) 2015-2026.

[45] F. Hollmann, K. Hofstetter, T. Habicher, B. Hauer, A. Schmid, Direct electrochemical regeneration of monooxygenase subunits for biocatalytic asymmetric epoxidation, J. Am. Chem. Soc. 127 (18) (2005) 6540-6541.

[46] S.H. Lee, D.S. Choi, M. Pesic, Y. Woo, C. Paul, F. Hollmann, C.B. Park, Cofactor-free, direct photoactivation of enoate reductases for asymmetric reduction of CC bonds, Angew. Chem. Int. Ed 56 (2017) 8681-8685.

[47] D.S. Choi, Y. Ni, E. Fernández-Fueyo, M. Lee, F. Hollmann, C.B. Park, Photoelectroenzymatic oxyfunctionalization on flavin-hybridized carbon nanotube electrode platform, ACS Catal. 7 (2017) 1563-1567.

[48] M. Mifsud, S. Gargiulo, S. Iborra, Arends I.W.C.E, F. Hollmann, A. Corma, Photobiocatalytic chemistry of oxidoreductases using water as the electron donor, Nat. Commun. 5 (2014).

[49] F.E. Zilly, A. Taglieber, F. Schulz, F. Hollmann, M.T. Reetz, Deazaflavins as mediators in light-driven cytochrome P450 catalyzed hydroxylations, Chem. Comm. (2009) 7152-7154.

[50] M. Mifsud Grau, J.C. van der Toorn, L.G. Otten, P. Macheroux, A. Taglieber, F.E. Zilly, I.W.C.E. Arends, F. Hollmann, Photoenzymatic reduction of CC double bonds, Adv. Synth. Catal. 351 (18) (2009) 3279-3286.

[51] F. Hollmann, A. Taglieber, F. Schulz, M.T. Reetz, A light-driven stereoselective biocatalytic oxidation, Angew. Chem. Int. Ed. 46 (16) (2007) 2903-2906.

[52] D. Holtmann, F. Hollmann, The oxygen dilemma: a severe challenge for the application of monooxygenases? Chembiochem 17 (2016) 1391-1398.

[53] P. Hemmerich, V. Massey, Flavin and 5-deazaflavin. A chemical evaluation of 'modified' flavoproteins with respect to the mechanisms of redox biocatalysis, FEBS Lett. 84 (1) (1977) 5-21.

[54] P.F. Heelis, B.J. Parsons, G.O. Phillips, A.J. Swallow, One-electron reduction of 5deazalumiflavin in aqueous solution: a pulse radiolysis study, Int. J. Radiat. Biol. 55 (4) (1989) 557-562.

[55] K. Tanaka, T. Okada, F. Yoneda, T. Nagamatsu, K. Kuroda, Preparation of chiral 5 deazaflavin derivatives and their asymmetric reduction of ethyl benzoylformate, Tetraherdon Lett. 25 (16) (1984) 1741-1742.

[56] M. Bliese, A. Launikonis, J. Loder, A. Mau, W. Sasse, Photoreduction of deazaflavin. spectroscopic investigations, Aust. J. Chem. 36 (1983) 1873-1883.

[57] M. Goldberg, I. Pecht, H.E.A. Kramer, R. Traber, P. Hemmerich, Structure and properties of 5-deazaflavin radicals as compared to natural flavosemiquinones, Biochim. et Biophys. (BBA) - Gen. Subj. 673 (Supplement C) (1981) 570-593.

[58] H.-J. Duchstein, H. Fenner, P. Hemmerich, W.-R. Knappe, (Photo)chemistry of 5Deazaflavin, Eur. J. Biochem. 95 (1) (1979) 167-181.

[59] W.R. Knappe, P. Hemmerich, H.J. Duchstein, H. Fenner, V. Massey, Photochemical formation of deazaflavin dimers, Biochemistry 17 (1) (1978) 16-17.

[60] G. Blankenhorn, Nicotinamide-dependent one-electron and two-electron (Flavin) oxidoreduction: thermodynamics, kinetics, and mechanism, Eur. J. Biochem. 67 (1) (1976) 67-80.

[61] M.S. Hossain, C.Q. Le, E. Joseph, T.Q. Nguyen, K. Johnson-Winters, F.W. Foss, Convenient synthesis of deazaflavin cofactor FO and its activity in F420-dependent NADP reductase, Organ. Biomol. Chem. 13 (18) (2015) 5082-5085.

[62] T. Knaus, C.E. Paul, C.W. Levy, S. de Vries, F.G. Mutti, F. Hollmann, N.S. Scrutton, Better than Nature: nicotinamide biomimetics that outperform natural coenzymes, J. Am. Chem. Soc. 138 (2016) 1033-1039.

[63] K.E. Taylor, J.B. Jones, Nicotinamide coenzyme regeneration by dihydropyridine and pyridinium compounds, J. Am. Chem. Soc. 98 (18) (1976) 5689-5694.

[64] R. Spencer, J. Fisher, C. Walsh, Preparation, characterization, and chemical properties of flavin coenzyme analogs 5-deazariboflavin, 5-deazariboflavin 5'-phosphate, and 5-deazariboflavin 5'-diphosphate, 5'- 5'-adenosine ester, Biochemistry 15 (5) (1976) 1043-1053.

[65] S. Salzmann, V. Martinez-Junza, B. Zorn, S.E. Braslavsky, M. Mansurova, C.M. Marian, W. Gärtner, Photophysical properties of structurally and electronically modified flavin derivatives determined by spectroscopy and theoretical calculations, J. Phys. Chem. A 113 (33) (2009) 9365-9375.

[66] M.T. Stankovich, V. Massey, Determination of the redox potential of deazariboflavin by equilibration with flavins, Biochim. et Biophys. Acta (BBA) - Enzymol. 452 (2) (1976) 335-344.

[67] R. Traber, H.E.A. Kramer, P. Hemmerich, Mechanism of light-induced reduction of biological redox centers by amino acids. A flash photolysis study of flavin photoreduction by EDTA and nitrilotriacetate, Biochemistry 21 (7) (1982) 1687-1693.

[68] K. Kitzing, T. B. Fitzpatrick, C. Wilken, J. Sawa, G.P. Bourenkov, P. Macheroux, T. Clausen, The 1.3 A crystal structure of the flavoprotein YqjM reveals a novel class of old yellow enzymes, J. Biol. Chem. 280 (30) (2005) 27904-27913.

[69] T.B. Fitzpatrick, N. Amrhein, P. Macheroux, Characterization of YqjM an old yellow enzyme homolog from Bacillus subtilis involved in the oxidative stress response, J. Biol. Chem. 278 (22) (2003) 19891-19897.

[70] V. Massey, P. Hemmerich, Photoreduction of flavoproteins and other biological compounds catalyzed by de-aza-flavins, Biochemistry 17 (1) (1978) 9-16.

[71] comment, It is interesting to note that within that period the characteristic peak for dRfox $(400 \mathrm{~nm})$ partially recovered (Fig. $3 \mathrm{BO}$ ) while it decreased again upon full reduction of YqjM. Most likely this can be attributed to the continuous photoreduction of dRfox in the reaction mixture by the excess of EDTA used to reduce it earlier

[72] A. Tosstorff, A. Dennig, A.J. Ruff, U. Schwaneberg, V. Sieber, K.M. Mangold, J. Schrader, D. Holtmann, Mediated electron transfer with monooxygenases-Insight in interactions between reduced mediators and the co-substrate oxygen, J. Mol. Catal. B-Enzym. 108 (2014) 51-58.

[73] F.W. Strohle, S.Z. Cekic, A.O. Magnusson, U. Schwaneberg, D. Roccatano, J. Schrader, D. Holtmann, A computational protocol to predict suitable redox mediators for substitution of NAD(P)H in P450 monooxygenases, J. Mol. Catal. BEnzym. 88 (2013) 47-51.

[74] M. Insińska-Rak, E. Sikorska, J.L. Bourdelande, I.V. Khmelinskii, W. Prukała, K. Dobek, J. Karolczak, I.F. Machado, L.F.V. Ferreira, A. Komasa, D.R. Worrall, M. Sikorski, Spectroscopy and photophysics of flavin-related compounds: 5-deazariboflavin, J. Mol. Struct. 783 (1) (2006) 184-190.

[75] V. Massey, Activation of molecular oxygen by flavins and flavoproteins, J. Biol. Chem. 269 (36) (1994) 22459-22462. 